\title{
EL CONCEPTO DE DEMOCRACIA: UN ANÁLISIS MULTIDIMENSIONAL
}

\section{THE CONCEPT OF DEMOCRACY: A MULTIDIMENSIONAL ANALYSIS}

\section{Diego Mauricio Hernández ${ }^{1}$}

Licença CC BY:

Artigo distribuído sob os termos Creative Commons, permite uso e distribuição irrestrita em qualquer meio desde que o autor credite a fonte original.
Abstract: This article starts with the semantic decomposition of the phrase demokratos, which states a subordination of "kratos" (government) to "demos" (people), and analyzes the concept of democracy from a multi-dimensional key. In order to elaborate on the concept of democracy, an analytical distinction was established around three dimensions of government subordination to the people: democracy is understood as (i) the government of the people, (ii) the government by the people, and (iii) the government for the people or the government that serves the people. This kind of analysis can establish a good state of art for contemporary discussions on democratic theory, and determine the main ways to improve the existing democratic government systems.

Key words:democracy, political representation, participation, accountability, political publicity, democratic responsiveness, social justice.

\section{(c) (i)}

Resumen: Este artículo presenta un análisis del concepto de democracia en clave multidimensional, partiendo de una descomposición semántica del sintagma demokratos, la cual establece una subordinación de "kratos" (gobierno) a "demos" (pueblo). Para estudiar el concepto de democracia se establece una distinción analítica en torno a tres dimensiones de la subordinación del gobierno al pueblo: (i) un gobierno del pueblo, (ii) un gobierno por el pueblo y (iii) un gobierno para el pueblo. Este análisis permite construir un estado del arte de buena parte de la discusión contemporánea sobre la teoría de la democracia, así como identificar las principales rutas de mejora institucional para los gobiernos democráticos existentes en la actualidad.

Palabras Clave: democracia, representación política, participación, rendición de cuentas, publicidad política, receptividad democrática, justicia social.

1 Researcher and Associate Professor at the Law School of Universidad de la Costa, Colombia, member of Derecho y Sociedad research group. Constitutional lawyer, $\mathrm{PhD}$ in philosophy, postdoctoral fellow. Social policy advisor. Current research areas: constitutional economic law, environmental comparative law, democratic innovation for sustainability, cosmopolitism, global democracy, theory of democracy. E-mail: dhernand47@cuc.edu.co 
¿Qué es exactamente la democracia? ¿Existe una única definición de democracia? ¿Es acaso un estándar mínimo o un objetivo que vale la pena perseguir pero que nunca se logra perfectamente?

Existen condiciones para considerar que un gobierno es una "democracia", de acuerdo con estándares formales y sustantivos. Sin embargo, el alcance de dichos estándares varía en función de la manera en que se comprende el concepto de democracia. Por tal motivo, es importante que la academia pueda contribuir con la elucidación de esta compleja noción. Hasta qué punto deben llevarse las prácticas y las instituciones llamadas "democráticas", es algo que depende, en línea directa, de la estructura del concepto de democracia, ya que éste es un concepto que busca guiar prácticas e instituciones. Es claro que este ejercicio no tiene una relevancia sólo metodológica. Por el contrario, un aporte a la comprensión de este concepto puede servir como guía para la mejora de las instituciones pretendidamente democráticas, a los estándares impuestos por el contenido conceptual de esta noción.

Este artículo presenta un análisis del concepto de democracia en clave multidimensional, partiendo de una descomposición semántica del sintagma demokratos, compuesto por la unión de "demos" (pueblo) y "kratos" (gobierno). Para elaborar el concepto de democracia se establece una distinción analítica en torno a tres dimensiones de la subordinación del gobierno al pueblo. La noción de democracia hace referencia a (i) un gobierno del pueblo, así como también a (ii) un gobierno por el pueblo y (iii) un gobierno para el pueblo. Este análisis permitiría construir un estado de buena parte de la discusión contemporánea sobre la teoría de la democracia. Se trata de una distinción únicamente analítica, pues las dimensiones son simultáneas y unitarias dentro del concepto de democracia, con lo cual es posible concluir que este modelo impone estándares sustantivos y formales en materia de representación, participación y transparencia.

En términos generales, la idea de democracia denota un cierto tipo de gobierno subordinado al pueblo, basado en el reconocimiento de la libertad de la persona y la igualdad existente entre todos los ciudadanos en las distintas etapas del proceso de toma de decisiones políticas. En virtud de la riqueza e idealidad de este concepto, existe las más de las veces una brecha entre teoría y realidad, lo cual invita a perfeccionar los sistemas democráticos. En contraste con el concepto de democracia, muchas "democracias" establecidas y relativamente estables todavía tienen un gran margen de mejora institucional. Considerar estas distintas dimensiones analíticas de la relación gobierno/pueblo permite proyectar las mejoras necesarias de una manera integral, no sesgada ideológicamente.

La prosperidad y la paz, objetivos asociados comúnmente a la idea de democracia, son argumentos aún más especulativos, los cuales, sin embargo, condicionan la validez de todo sistema democrático. Los distintos procesos de democratización en el mundo han dejado a un gran número de democracias emergentes en Asia, África y América Latina desprovistas de una base de legitimidad, lo cual ha impedido a muchos países consolidar una estabilidad política a través de la democracia. 
Los frecuentes conflictos y la situación de pobreza masiva han llevado, en muchos casos, a un auténtico fracaso social del modelo. En cualquier caso, la democracia es una tendencia mundial y un valor político reconocido por casi todos los países del mundo. El sistema democrático es más que sólo una parte y un componente importante de la gobernanza nacional. En cierto sentido, la democracia, al establecer una subordinación del gobierno frente al pueblo, es la base de legitimidad del Estado contemporáneo, el cual se concibe como resultado de un contrato político entre una comunidad de individuos libres que tienen el propósito común de conseguir una vida buena. Por tal motivo, los objetivos de paz, prosperidad y estabilidad social están indisociablemente asociados a la idea de democracia, a pesar de no estar incorporados en el concepto mismo. En consecuencia, si un sistema democrático no cumple con tales expectativas y no es capaz de resolver los problemas más apremiantes de la sociedad, en última instancia, se convierte en un sistema poco confiable e injustificado.

La democracia contemporánea tiene la pretensión de mejorar el nivel de organización de la política, sirviendo de esta manera a la política misma, pero incorpora también el objetivo social de mejorar el nivel de vida de la población. Por lo tanto, las exigencias formales de la democracia no deben convertirse en obstáculos para dar respuesta a las necesidades apremiantes de la sociedad. Un ejemplo palpable de este riesgo ha sido el manejo que muchos gobiernos elegidos democráticamente han dado a la pandemia por Covid-19. En virtud de sesgos ideológicos y de una malcomprensión de la democracia, muchos gobiernos han carecido de liderazgo, y se han mostrado egoístas e incompetentes, convirtiendo a la democracia en una maraña de falacias políticas plagadas de errores populistas. La democracia, por el contrario, debe ser ejercida como una forma de gobierno capaz de resolver los apremios del pueblo, pues se trata de una forma de gobierno que le está subordinada.

Desde el punto de vista teórico y práctico, es indispensable que el análisis del concepto permita desencantar la democracia y eliminar la carga ideológica asociada a tal noción. Una concepción multidimensional permitiría examinar las reformas e innovaciones necesarias a partir de una interpretación analítica de la idea de democracia, donde eventualmente se ver recogidas la mayor parte de las perspectivas particulares ${ }^{2}$. Como ha anotado David Estlund (2008), si bien los principios democráticos encarnan un concepto idealizado de legitimidad democrática, es fundamental que las democracias realmente existentes se acerquen a dicho ideal, para evitar que la práctica termine por aniquilar las aspiraciones conceptuales del concepto de democracia.

2 Una concepción minimalista supone que una democracia puede estar en contradicción con la justicia social, pues, conceptualmente, no existe una armonía preestablecida, sino más bien una relación problemática; "the relation between democracy and justice, very far from expressing a pre-established harmony, is on the contrary highly problematic" (Van Parijs, 2011, p. 7). 


\section{UN CONCEPTO MULTIDIMENSIONAL DE DEMOCRACIA}

El concepto de democracia establece una relación de subordinación multidimensional del gobierno (kratos) con respecto al pueblo (demos). La propuesta de interpretación que aquí se presenta está inspirada en la definición presentada por Abraham Lincoln, en el Discurso de Pennsylvania de 1864. En su discurso, Lincoln afirmó: "Democracy is a government of the people, by the people, for the people" (la democracia es un gobierno del pueblo, por el pueblo, para el pueblo). Esta fórmula permite de-construir el concepto de democracia haciendo énfasis en la circularidad y cierre que constituyen la noción. Un análisis conceptual de la democracia con la fórmula Lincoln muestra la manera en que este modelo establece una relación de circularidad con el pueblo, donde el pueblo es origen, finalidad y agente del gobierno. El gobierno se ubica como punto medio entre el pueblo y el pueblo mismo, ya que, de acuerdo con la fórmula de interpretación adoptada, en la democracia, el gobierno pertenece al pueblo (government of the peolple), el gobierno es ejercido por el pueblo (government by the people), y el gobierno está al servicio del pueblo (government for the peolple).

La democracia moderna es una forma de gobierno subordinada a una comunidad de personas libre e iguales, que permite a los individuos tener el control autónomo de sus propias vidas. La vida de cada individuo está profundamente influenciada por el entorno social, legal y cultural más amplio, por lo cual el control de la propia vida implica también el que cada uno tenga el mismo derecho a participar y votar por la conformación del poder político. Carol Gould (1988) sostiene que sólo mediante la implementación de la democracia los individuos están en verdaderas condiciones de gobernarse a sí mismos. Cassese (1995), por su parte, argumenta que el derecho a la autodeterminación colectiva requiere un sistema democrático que otorgue a los ciudadanos control colectivo sobre sus estructuras políticas y legales.

El principio de igualdad exige de la democracia adoptar una posición neutral frente a las demandas e intereses presente en la sociedad. La democracia debe respetar los distintos puntos de vista y dar a todos una voz igual en la toma de decisiones (Singer, 1973; Waldron, 1999). Esta forma de gobierno constituye un mecanismo igualitario donde los intereses en conflicto pueden tramitar sus diferencias, dando una forma común a la sociedad.

Más aún, la democracia, como auto-gobierno de la comunidad, da lugar a un sistema político regido por el debate libre y racional entre iguales. Según Jürgen Habermas (1996), la democracia, desde el punto de vista de la teoría del discurso, da lugar a leyes y normas aceptables para los ciudadanos, al ser fruto de un debate racional. Por tal motivo, Habermas encuentra una riqueza de la democracia en el debate parlamentario e institucional, así como en el diálogo político informal entre los ciudadanos. En este mismo sentido, de acuerdo con Joshua Cohen (1996), la legitimidad de las leyes democráticas reposa en la existencia de motivaciones y razones mutuamente aceptables, fruto de un adecuado procedimiento deliberativo entre individuos libres en pie de igualdad. El aspecto 
deliberativo de la democracia, de acuerdo con Cohen, exige que los individuos proporcionen razones que otros puedan aceptar racionalmente, pues, como se ha visto, los interlocutores en el debate son individuos libres e iguales. La teoría deliberativa de la democracia contemporánea es un desarrollo del clásico planteamiento rousseauniano, según el cual la voluntad general (volonté générale) es más que la suma de voluntades individuales pues es producto de un proceso democrático bien organizado, fruto de un debate racional entre individuos libres e iguales (Rousseau, 1762). El propósito deliberativo es un aspecto fundamental de la democracia, pues es el mecanismo que garantiza que la obediencia a la ley tenga lugar como obediencia a la voluntad general, al bien común, y no como obediencia a una voluntad particular (Stilz,2009).

\section{PRIMERA DIMENSION ANALÍTICA: EL GOBIERNO DEL PUEBLO}

La primera dimensión analítica, revelada por la fórmula Lincoln, en cuanto a la relación del gobierno con el pueblo equivale a "the government of the people". La preposición "of" puede ser interpretada filosóficamente como denotando al pueblo como el poder constituyente del gobierno. El pueblo es el poder constituyente de gobierno democrático. En una democracia, el pueblo da lugar a una forma de gobierno colectivo, mediante un procedimiento de delegación del ejercicio del poder político, dentro de unos límites y lineamientos definidos constitucionalmente. El acto de delegación de poder político en las instituciones se expresa a través del mecanismo electoral. Se da cuenta, en esta dimensión, del aspecto representativo de la democracia. Esta dimensión del concepto de democracia puede ser expresada como "a form of collective decision-making that combines three elements: free voting, universal sufrage and majority rule" (Van Parijs, 2011, p. 1). Se refleja, con esta dimensión, una parte importante de lo que en el mundo contemporáneo se asocia mayoritariamente con la democracia.

El asunto de la representación política es, sin duda, un punto central en el concepto de democracia, pues la regla de la mayoría, en una comunidad tan amplia como una comunidad nacional contemporánea, implica la existencia de mecanismos de representación. Sin embargo, es importante anotar que dicha centralidad ha implicado, en muchos casos, que la formula democrática haya quedado reducida al eslogan: "mientras haya elecciones, la democracia está representada". A pesar de su centralidad, la representación política no debe servir como cortina de humo para justificar, tras un sistema representativo, deficiencias de política pública y fallas de gobernabilidad.

El principio básico de la representación democrática (una persona, un voto) consiste en que las personas deben tener la misma capacidad para elegir y ser elegidos en los cargos de representación. La teoría de la democracia ha diseñado mecanismos de representación política adaptados a sociedades complejas, a saber, la representación por distritos uninominales (single member district representation), la representación proporcional (proportional representation) $)^{3}$ y la representación de

3 La representación proporcional permite a los partidos políticos competir por un porcentaje de escaños de representación según el número total de votos conseguidos entre la población electoral. 


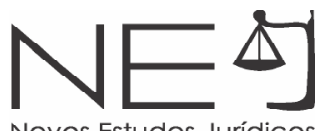

grupo (group representation) ${ }^{4}$. Estos distintos esquemas de representación son utilizados de manera combinada las democracias contemporáneas, con la intención de lograr que la comunidad pueda estar adecuadamente representada en las instancias legislativa y gubernamental.

El mecanismo de representación por distritos uninominales elige un único representante por cada área geográficamente definida, estimando que cada área contiene poblaciones aproximadamente iguales. Como resultado, al garantizar a cada área geográfica una misma representación, se estaría garantizando una igual cuota de representación a cada votante individualmente considerado. El mecanismo de la representación por distritos uninominales se justifica porque, dentro de un contexto de competencia política, la reducción de los posibles representantes brinda una mayor estabilidad política y crea en los candidatos una mayor disposición a tener una agenda abierta a la concertación, pues este procedimiento exige elaborar propuestas capaces de seducir a un espectro social más amplio que el propio partido político (Beitz, 1989).

Se ha puesto en evidencia la tendencia de este mecanismo hacia el fortalecimiento de una democracia bipartidista, basada en la conquista del votante medio (Christiano y Sammer, 2021). Se ha argumentado que la representación uninominal por circunscripciones geográficas estimula la creación de acuerdos entre distintos partidos y movimientos minoritarios y mayoritarios, pues los pequeños movimientos, aisladamente considerados, están en incapacidad de conquistar la mayoría política, con lo cual el espectro político se ver reducido a dos partidos mayoritarios. La tendencia al bipartidismo, propia de este modelo de representación, incorpora en la agenda política de partidos políticos y grupos de interés, una serie de cualidades de negociación y diálogo, que se convierten en necesarias para tener éxito en una democracia.

Una crítica fuerte al modelo de representación uninominal por distritos geográficos consiste en señalar que este esquema netamente pro-mayoritario tiende a anular la voz e intereses de los grupos minoritarios en la sociedad (Christiano, 1996). Si bien es cierto que este modelo promueve el diálogo entre movimientos mayoritarios y minoritarios, la dinámica real de negociación suele relegar las aspiraciones de las minorías en un segundo plano, con el resultado de dejar a los grupos minoritarios sub-representados, en el marco de una negociación desigual con los partidos mayoritarios (Christiano y Sammer, 2021).

Una alternativa para resolver el problema de la subrepresentación de minorías ha sido desarrollada en el marco del modelo de la representación proporcional. En este modelo, si un porcentaje del electorado apoya a un partido político, consigue ese mismo porcentaje de los escaños disponibles, sin un cierre formal a una única candidatura (ACE, 2014). La aspiración de la representación proporcional es dar un mayor peso a cada voto individual y no sólo a los votos mayoritarios, garantizando, hasta cierto punto, que los partidos políticos minoritarios puedan conseguir una representación proporcional en la instancia electoral. Para este propósito, este

$4 \quad$ La representación de grupo identifica grupos poblacionales (grupos étnicos o lingüísticos) o incluso grupos funcionales (trabajadores, agricultores), garantizando que tales grupos tengan escaños de representación. 
esquema introduce la idea de distritos plurinominales, pues se sostiene que no es posible lograr una representación proporcional con un único partido representante (IDEA, 2005). Sin embargo, en este marco, sigue siendo factible que las minorías resulten relegadas, al no alcanzar los umbrales de votación necesarios para conseguir un campo en la instancia legislativa.

El esquema de la representación de grupos pretende superar el problema de subrepresentación de las minorías identificado en los sistemas de representación uninominal y proporcional (Young, 1990). Este modelo pretende garantizar que los grupos minoritarios aseguren un lugar en la instancia legislativa, de manera que las minorías no necesiten hacer que sus demandas se ajusten a las mayorías partidistas. De acuerdo con Iris Marion Young (1990), la única forma de proteger los intereses de las minorías es garantizar legalmente que se establezcan cuotas de representación obligatoria para determinados grupos minoritarios, incluso si esta representación resulta "desproporcionada".

La discusión teórica sobre la representación política no se agota en la construcción de esquemas electorales. Este ámbito de la discusión ha dado lugar a reflexiones sobre la ética de los representantes. Es importante recordar que en la democracia representativa el pueblo es la esencia del poder político. Por lo tanto, es posible afirmar que el pueblo, y no sus representantes, es el titular de dicho poder. Por tanto, los representantes, como representantes del pueblo, deben obedecer el juicio de sus ciudadanos. Debido a que el pueblo permite que los representantes gobiernen, es natural que los representantes sean responsables ante su comunidad. Si los representantes no fueran responsables ante el pueblo, la ciudadanía perdería toda posibilidad de ejercer control político, abandonando su rol democrático como esencia del poder.

En relación con la responsabilidad ética de los representantes democráticos, Hanna Pitkin (1967) introduce una célebre distinción entre trustees (fideicomisarios) y delegates (delegados). Según el análisis de Pitkin, es necesario definir si los representantes democráticos son fideicomisarios o delegados, pues esto determina su grado de subordinación con respecto al pueblo. Un enfoque tecnocrático privilegiaría la consideración de los representantes como fideicomisarios, quienes tendrían plena autonomía para llevar a cabo sus funciones. Según este enfoque, los funcionarios públicos están más capacitados que los ciudadanos comunes para tomar decisiones políticas razonables y adecuadas para la comunidad. Un enfoque estrictamente democrático, en cambio, consideraría que la representación es un mecanismo mediante el cual la ciudadanía misma determina las metas sociales. Por tanto, se concibe al representante político como un delegado, cuyos juicios y opiniones deben guardar coherencia con las aspiraciones del electorado (Christiano, 1996).

La existencia de una dimensión de justicia política es el primer fundamento de la autoridad democrática. David Estlund (2008) considera que los procedimientos democráticos tienen una autoridad legítima por ser capaces de producir decisiones aceptables para todos los ciudadanos racionales. Dado que la democracia instaura un pie de igualdad entre los ciudadanos, algunos autores sostienen que desobedecer la decisión de un parlamento democrático equivale a tratar a los propios 


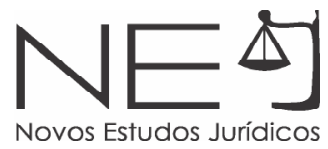

compatriotas como inferiores y a desconocer el derecho igualitario de todos los ciudadanos a tener voz en la promulgación de leyes (Christiano, 2008).

Ahora bien, muchos gobiernos son catalogados políticamente como "democracias", por llevar a cabo elecciones de forma regular, creyendo que con el reconocimiento del derecho al sufragio universal es suficiente para que exista una democracia. Este tipo de pensamiento es ingenuo, pues desconoce la complejidad del concepto. Es indudable que las elecciones por sí solas no necesariamente implican que exista una verdadera democracia y mucho menos un buen gobierno. Una democracia, como se ha hecho evidente en este artículo, requiere más condiciones que sólo las elecciones.

Sin lugar a dudas, en una democracia es importante que existan elecciones regulares, pues debe existir una rotación en el uso del poder político, y no un monopolio, pues lo intereses en el pueblo son diversos. La democracia tiene la virtud de asegurar una rotación pacífica del poder, basada en elecciones con criterios de transparencia, de manera que logre evitar la brutalidad de la violencia política. Como mecanismo político electoral abierto y regular, la democracia da un cauce pacífico y ordenado a la competencia por el poder público. La democracia electoral asegura, teóricamente, la apertura del sistema político a la diversidad y garantiza que toda la ciudadanía tenga las mismas oportunidades para compartir el poder político, mediante la rotación periódica de los cargos de elección popular. En el concepto de democracia, el poder político es entendido como un bien "propiedad del pueblo" o un bien público, por lo cual, mediante las elecciones regulares, se busca que este poder político pueda transitar de unas manos a otras.

El fenómeno de la rotación de partidos políticos en el poder, no obstante de ser un mecanismo de paz política, debilita la implementación de estrategias a largo plazo. En virtud de la rotación de partidos, en efecto, es posible que se dificulte llevar a cabo estrategias de continuidad, dejando a las economías nacionales sobreexpuestas a las crisis. La diversidad de intereses presentes en la sociedad puede llevar a que los gobiernos adopten estrategias contradictorias entre sí, pues los intereses nacionales están, en muchos casos, en franca oposición. Cuando los gobiernos democráticos son incapaces de resolver problemas sociales y económicos de manera efectiva, se convierten en objeto de múltiples críticas y se generaliza un ambiente de duda con respecto al funcionamiento de la democracia misma.

Durante el proceso electoral tiene lugar una competencia entre líderes de diferentes partidos, quienes suelen entrar en duras peleas e insultos mutuos durante las campañas, con lo cual se erosiona el propósito deliberativo de la democracia. Además, la incursión de los gremios económicos, hace en muchos casos de las elecciones una competencia de intereses entre empresarios, más que a una expresión democrática basada en la voluntad del pueblo.

Cuando la "democracia" se reduce al proceso electoral no logra jugar un papel positivo en la construcción democrática del sistema político. La representación política parece ser un mecanismo indispensable y necesario para que exista una democracia, mas no suficiente, pues la esencia de la 
democracia no es otra que permitir que la voluntad del pueblo se manifieste de manera efectiva a través del gobierno, en tanto elector, ciertamente, pero también en cuanto agente y en tanto finalidad.

\section{SEGUNDA DIMENSION ANALÍTICA: EL GOBIERNO POR EL PUEBLO}

La segunda dimensión analítica del concepto de democracia denota una relación de subordinación del gobierno al pueblo, la cual es expresada en la aserción "the government by the people". La preposición "by" o "por" trae a cuento a un agente que realiza una acción y a un instrumento a través del cual esta acción se realiza. Agente e instrumento corresponden a pueblo y gobierno, respectivamente.

Filosóficamente, recapitulando, se puede afirmar que el pueblo es la materia constituyente, la cual da lugar a una forma estatal para ejercer el auto-gobierno, a través de un instrumento. Esta dimensión de la relación explica la importancia democrática que tienen los principios de participación ciudadana y capacidad de respuesta por parte de las instituciones.

Las primeras dimensiones del concepto de democracia democracia, expresadas como the government of the people, the government by the people, puede esquematizarse de la siguiente manera:

\begin{tabular}{|c|c|}
\hline \multicolumn{2}{|c|}{ Relación pueblo/gobierno } \\
según "the government by the people" \\
\hline Pueblo & Gobierno \\
\hline Poder constituyente & Forma \\
\hline Agente & Instrumento \\
\hline
\end{tabular}

Esta segunda dimensión de la subordinación del gobierno al pueblo, al sugerir que el poder político es un instrumento a través del cual el pueblo ejerce el gobierno, ha dado lugar a un desarrollo profundo de la democracia participativa. La democracia participativa enfatiza la participación de todas las personas en el funcionamiento del sistema político. En contraste con la democracia representativa tradicional, el paradigma de la participación ciudadana tiene la pretensión de involucrar a la comunidad en la toma de decisiones.

La reducción de la democracia al plano representativo hace que el papel de los individuos se limite básicamente a la elección de representantes. Incluso si cada individuo participa en la democracia al emitir un voto en la actividad electoral, no sólo el impacto del voto en el resultado de las elecciones es mínimo, sino que el momento del vota no agota el ámbito de la participación política. La democracia participativa pretender incrementar la participación de la ciudadanía en el ejercicio del gobierno, desafiando la reducción de la democracia a la representación (Reveles Vázquez, 2017). 
Se ha considerado que el desarrollo participativo de la democracia es conceptualmente necesario, partiendo de una noción de la democracia como auto-gobierno de una comunidad de personas libres e iguales. Solo cuando cada individuo tiene la oportunidad de participar directamente en la toma de decisiones relacionadas con su propia vida, puede decirse que controla verdaderamente el proceso de su vida de manera autónoma.

La democracia participativa ha sido presentada como una "democracia de contenido", en contraste con una democracia representativa meramente "formal". La democracia restringida a la representación limita la participación ciudadana al momento del voto, excluyendo al pueblo de la definición de los contenidos de política construidos por los representantes. El paradigma participativo, en cambio, constata que la democracia es un proceso continuo, destinado a hacer las políticas públicas más acordes con las necesidades de la sociedad (Crouze, 2014).

La democracia participativa pone sobre la mesa un conjunto de nuevos procedimientos democráticos, orientados a abrir la política a la ciudadanía y promover un estilo de vida social activo. La democracia participativa no solo hace hincapié en la realización de la democracia en el ámbito político, sino que también aboga por la realización de la democracia en el plano social. La participación democrática es concebida, no sólo como una forma de gobernanza política. Este tipo de participación es considerada en sí misma como un estilo de vida social que existen buenas razones para valorar (Arellano, 2015). La participación democrática incentiva una vida social activa, en la medida en que está relacionada con un sentido de eficacia política de las propias acciones.

La democracia participativa busca dar una mayor voz a los ciudadanos y las organizaciones de la sociedad civil, incrementando su capacidad para participar en los asuntos públicos. Se aboga por el fortalecimiento de la participación de la ciudadanía en la vida social y política, en ámbitos principalmente relacionados con la vida cotidiana de las personas. Se busca, así, reforzar la efectividad, eficiencia y legitimidad de la política pública, al dotarla de un reconocimiento comunitario (Crouze, 2014).

El eslabón más crítico para lograr una gobernabilidad democrática participativa se encuentra en el nivel de la gobernanza rural, donde es necesario fortalecer la confianza de la población en la institucionalidad, de manera que sea posible crear un auténtico entusiasmo de cara a la participación en política. Mediante la incorporación de la participación activa de la población, la política pública adquiere un carácter de diálogo social, el cual favorece la creación de una confianza estable en las instituciones a nivel local. Por tal razón, la incorporación de la población rural en el proceso de implementación de la política puede contribuir a mejorar el orden público y la convivencia en el campo.

Existe un gran reto en materia de innovación democrática, en relación con la gobernabilidad participativa rural. Las estrategias de participación diseñadas deben, por supuesto, contribuir a modernizar la gobernabilidad rural y aumentar el nivel de confianza en la institucionalidad, 
estableciendo un mecanismo de participación sólido, para lograr una situación estable de gobernanza social. La realización de la democracia requiere que el estado de derecho proporcione un entorno estable para la participación, donde sea posible canalizar el entusiasmo y la vitalidad participativa del pueblo. Por tal motivo, la realización del concepto de democracia como gobierno por el pueblo (segunda dimensión analítica), exige el desarrollo y la modernización de la gobernabilidad rural. La democracia debe facilitar el desarrollo de la gobernabilidad rural, a través de la participación de la comunidad en política pública, fortaleciendo las capacidades de gobierno en un proceso de promoción continua de la democracia. La innovación y el desarrollo de tecnologías democráticas debe propender por la promoción de la sociedad de base rural.

El principio de participación enfatiza también la importancia de la transparencia, la consulta, la deliberación y el control sobre la implementación de las políticas públicas. Este paradigma sugiere que el gobierno vuelve a su posición de subordinado del pueblo, inculcando así una cultura de control del gobierno por parte del pueblo (Crouze, 2014).

La democracia contemporánea ha incorporado el principio de la transparencia y la rendición de cuentas (accountability), fortaleciendo el principio de un gobierno por el pueblo (by the people). En la política democrática, los funcionarios electos y designados deben rendir cuentas al pueblo y asumir responsabilidades (Philp, 2009). Para que este principio democrático pueda hacerse efectivo a través del mecanismo de la rendición de cuentas, un tal sistema debe cubrir todos los niveles de la administración, a fin de garantizar que no falten eslabones en la cadena de responsabilidad.

El sistema de rendición de cuentas no solo incluye un régimen sancionatorio para funcionarios, sino que, fundamentalmente, exige que el gobierno "rinda cuentas" al público. Los funcionarios tienen la responsabilidad de informar de sus acciones al público, y los ciudadanos tienen derecho a exigir sanciones contra los funcionarios que se comportan indebidamente. Este mecanismo estrecha el vínculo entre el pueblo y el ejercicio del gobierno.

La idea de un gobierno transparente y un manejo abierto de asuntos gubernamentales, responde a la misma premisa de acercamiento del pueblo al ejercicio del gobierno, mediante la apertura y el público conocimiento de los expedientes oficiales. Un gobierno responsable ante el pueblo, con el propósito democrático de involucrar al pueblo en el ejercicio del poder político, debe permitir que éste pueda estar debidamente informado. Si el público no tiene acceso a la información, se hace incapaz de vigilar el cumplimiento del deber. Solo cuando un gobierno es transparente y los asuntos gubernamentales están abiertos, ese gobierno y esos funcionarios pueden ser puestos bajo supervisión pública.

La democracia precisa abrir los canales de la opinión pública y respetar y movilizar plenamente el entusiasmo del pueblo por la participación política, a través de mensajes asertivos y pertinentes. El principal objetivo de la publicidad pública debe ser desarrollar la conciencia del pueblo sobre 
los valores y la ética de la participación democrática. En este sentido, es esencial garantizar una dinámica proactiva por parte de los medios de comunicación y contar con canales de difusión por redes sociales, destinados a fortalecer la veeduría de la sociedad en los procesos de toma de decisiones gubernamentales.

Sin embargo, existen buenas razones para desconfiar de las verdaderas intenciones propagandísticas que se esconden detrás de la publicidad política. El profesionalismo, la ética social y la alfabetización mediática del público podrían contribuir a mitigar los riesgos asociados a la publicidad política. Sin duda, es relevante para la población poder decidir críticamente si está dispuesto, o no, a aceptar la propaganda de la gobernanza moderna y la manipulación de la información como medio de control social, rasgos que se han convertido en constantes en la sociedad moderna.

Se puede decir que el concepto de "propaganda" tiene un manto de duda sobre su legitimidad, incluso en la época contemporánea, donde la propaganda política ha sufrido cambios y actualizaciones. A pesar de la mayor sofisticación en la publicidad, que se manifiesta en la incorporación de la ciencia, las artes y las humanidades, sigue siendo válida la cuestión de si es legítima o ilegítima la propaganda política, en la medida en que tergiversa la relación entre gobernantes y gobernados (Klein, 2001).

Es válido preguntarse cómo es posible construir verdaderos consensos a través de la publicidad política y dónde se encuentra el límite ético de la propaganda. Es importante definir el alcance del proceso dinámico de comunicación constante, permitiendo un libre juego. Dentro de un contexto de competencia política, debe ser posible la construcción conjunta de una regulación sobre los límites de la comunicación política y sus alcances, considerando la importancia de promover la diversidad étnica y cultural.

El que gobernantes y gobernados estén conectados a los medios de comunicación, permite la difusión a escala masiva de la propaganda política, con propósitos de persuasión y control social. Al mismo tiempo, sin embargo, debido a que las piezas de propaganda política siguen determinados libretos, la función de los líderes políticos termina reducida a ser simples marionetas. Sin embargo, es forzoso reconocer que gobernar el medio ambiente político, a su vez, influye en las actitudes políticas de la población, los juicios de valor y el entusiasmo popular por la participación política.

\section{TERCERA DIMENSION ANALÍTICA: EL GOBIERNO PARA EL PUEBLO}

La tercera dimensión de la relación entre el gobierno y el pueblo está definida por la fórmula: "the government for the people". La preposición "for" o "para" es interpretada aquí como denotando "en favor de quien" ha de orientarse la política democrática. El gobierno democrático está en favor del pueblo, pues ese pueblo es el fin único declarado en el concepto de democracia. El gobierno, en cambio, es sólo un medio para ese fin. En esta tercera dimensión del concepto de democracia, el gobierno, emanado del pueblo, regresa al pueblo. Este regreso al origen es necesario para completar 
la circularidad del concepto y así confirmar la referencia exclusiva del gobierno al pueblo, esencial al concepto de democracia.

Es posible recapitular señalando que la relación pueblo/gobierno, establecida de manera multidimensional en el concepto de democracia, determina la posición del gobierno y el pueblo, de acuerdo con el tablero siguiente:

\begin{tabular}{|c|c|}
\hline \multicolumn{2}{|c|}{ Relación pueblo/gobierno } \\
según «the government of the people, by the people, for the people» \\
\hline Pueblo & Gobierno \\
\hline Materia & Forma \\
\hline Agente & Instrumento \\
\hline Fin & Medio \\
\hline
\end{tabular}

Se ha argumentado que la democracia tiene la capacidad de proteger los derechos o intereses de las personas, en la medida en que es un sistema sensible a los juicios y preferencias del pueblo. Al incluir a las personas, las comunidades y los grupos en el proceso democrático, el sistema político de la democracia podría estar capacitada para promover los diversos intereses de una mejor manera (Wright, 2013). Inclusive, se ha sostenido que la democracia es un sistema que promueve el crecimiento económico de toda la población, al incorporar en su agenda los intereses de toda la población y no sólo de grupos en particular (Acemoglu, 2019). La literatura contemporánea ha señalado que un sistema democrático es la forma de gobierno más favorable para garantizar la protección efectiva de los derechos fundamentales, en un marco de libertad e igualdad (Gaus, 1996; Christiano, 2011; Gaus, 2011). En este sentido, Amartya Sen ha señalado que "no substantial famine has ever occurred in any independent country with a democratic form of government and a relatively free press (1999, p. 152).

Esta tercera dimensión analítica del concepto de democracia, vista como el gobierno para del pueblo, ha dado lugar a una justificación del modelo en virtud de tener una mayor capacidad para la creación de políticas adecuadas, debido a su mayor capacidad de dar respuesta a las necesidades sociales. Desde distintos enfoques se ha sostenido que la democracia tiene una estructura epistémica capaz de generar respuestas legales y políticas adaptadas al contexto y con alta calidad. El argumento epistemológico democrático sostiene que, en las condiciones adecuadas, la democracia es un mecanismo ideal para la toma de decisiones políticas correctas. 
Una defensa clásica de este principio es el célebre Teorema de Condorcet. Según este teorema matemático, dadas ciertas condiciones, la probabilidad de que la mayoría de los votantes apoyen la decisión correcta aumenta a medida que el número de votantes aumenta (Condorcet, 1785). Teóricos contemporáneos como List y Goodin (2001) han insistido en la vigencia de este teorema, aún para decisiones democráticas complejas, con más de dos opciones (Barry, 1965; Cohen, 1986; Grofman and Feld 1988; Goodin y Spiekermann, 2019).

El planteamiento original de Condorcet está basado en tres supuestos, los cuales han sido objeto de amplia discusión. Condorcet asume que: (i) cada votante tienen la competencia para escoger la opción correcta, (ii) cada votante es sincero consigo mismo al momento de votar por quien su criterio le indica es el mejor; (iii) los votantes son independientes entre sí. Los críticos del teorema de Condorcet sostienen que las suposiciones detrás del planteamiento son poco realistas en la democracia contemporánea, pues, en un contexto partidista, las opiniones de los votantes no son independientes entre sí. En la práctica, además, no tiene lugar el presupuesto de la sinceridad de los políticos, pues existen marcados sesgos partidistas (Anderson, 2006). Más grave aún, no existe una información perfecta con la cual todos los votantes pudieran estar adecuadamente informados sobre los procesos de toma de decisión (Black, 1963; Ladha, 1992; Estlund, 1997; 2008).

Una defensa epistemológica de la democracia, separada del teorema de Cordorcet (1996), rescata la capacidad de este modelo político de sacar provecho de la diversidad cognitiva y cultural de la ciudadanía. Los procedimientos de participación democrática permiten que la política publica, más que una mera agregación de preferencias individuales, sea resultado del diálogo entre las distintas perspectivas presentes en campo (Waldron 1995). Al involucrar a una diversidad de personas en el proceso de toma de decisiones, la democracia hace uso de una variedad de fuentes de información y opiniones para diseñar y evaluar las leyes y políticas más adecuadas.

Dicha ventaja epistemológica de la democracia, asociada a una mayor calidad de las leyes y políticas producidas por la participación democrática, ha sido formalizada por Scott Page y Lu Hong, a través del "diversity-trumps-ability theorem" (Hong y Page, 2004; Page, 2007). Este teorema señala que las decisiones tomadas por un grupo de individuos extraídos al azar de un gran número de personas con capacidades "limitadas", son generalmente mejores que las decisiones tomadas por una selección de los individuos más sobresalientes del mismo grupo (Landmore, 2013). Se concluye, por lo tanto, que la participación democrática puede producir mejores decisiones que un gobierno de expertos (Quirk, 2014; Brennan, 2014; Thompson, 2014; Bajaj, 2014).

En virtud de la referencia del concepto de democracia al pueblo, como origen y como finalidad de del gobierno, es posible afirmar que un estado democrático únicamente puede alcanzar una estabilidad social y política en la medida que consigue llevar a la práctica los principios de justicia política y social. En una democracia, el poder político surge del pueblo, con el objetivo y la finalidad de servir a ese mismo pueblo, por lo que la política democrática formal debe incorporar la práctica 
de la justicia política y social. La democracia no solo garantiza la aceptabilidad de las normas de distribución del poder público, sino que también mantiene la apertura de la agenda política a las necesidades sociales del pueblo.

La igualdad y la libertad, como se vio más arriba, son los principios fundamentales de la democracia, por lo cual, desde el punto de vista de la justicia social, una sociedad democrática debe ser una sociedad igualitaria y respetuosa de las libertades individuales. La libertad y la igualdad son el origen de la democracia, se manifiestan inevitablemente como participación activa en el gobierno, y se presentan como la finalidad misma de la democracia. En la circularidad del concepto de democracia encontramos el principio primordial de la ética política de este modelo.

El objetivo básico de la justicia, en una sociedad democrática, es promover la libertad individual y favorecer el desarrollo de la igualdad social. La libertad y la igualdad, como ética política democrática, tienen un valor independiente en sí mismo, al tiempo que también se manifiestan a través de otros elementos de valor. En este sentido, para avanzar en la realización de la justicia social, es necesario resolver efectivamente los problemas de igualdad sustantiva y formal, en sus distintos ámbitos. En efecto, en la sociedad contemporánea, promover la justicia procedimental es un requisito básico para perfeccionar la igualdad en sentido material y la ética política de la justicia formal. Así, la resolución de problemas sociales complejos, la evaluación de una determinada política e incluso la corrección de un cierto error, deben reflejar la ética democrática de la igualdad y la libertad.

El proceso democrático no puede privar a los ciudadanos de los derechos políticos. En efecto, no debe afectar los derechos necesarios para el proceso democrático, como la libertad de asociación o la libertad de expresión. La democracia, sin embargo, va más allá de este límite, mostrando que los derechos que no son esenciales para el ejercicio del derecho al sufragio, en particular los derechos sociales, deben ser igualmente protegidos. La premisa teórica es que los derechos de libertad se basan en la igualdad social, por lo cual la democracia está obligada a garantizar los mínimos económicos y sociales (Ely, 1980).

Las obligaciones de la democracia con la justicia social constituyen, por su parte, el fundamento de justificación de la desobediencia civil. En efecto, la desobediencia civil ha sido vista como el mecanismo a través del cual los ciudadanos pueden promover la justicia social y política en una democracia. La desobediencia civil es concebida como una violación abierta de la ley, no violenta y consciente, orientada a cambiar leyes o políticas gubernamentales (Bedau, 1961; Rawls, 1971). Según la teoría estándar de la desobediencia civil, las personas que llevan a cabo el acto desobediente deben estar dispuestas a aceptar las consecuencias legales de sus acciones, para mostrar su lealtad con respecto al derecho. Sin embargo, se ha argumentando que las acciones de desobediencia de personas que intentan evadir las consecuencias legales también pueden considerarse como desobediencia civil. (Raz, 1979; Brownlee 2004, 2007, 2012). 
La desobediencia civil es un paradigma según el cual las mismas consideraciones que fundamentan la obligación de obedecer la ley, en determinadas condiciones, hacen que sea apropiado que los ciudadanos desobedezcan la ley (Rawls, 1971; Sabl 2001; Markovits 2005; Smith 2011). Por ejemplo, Rawls (1971) considera que aún en una sociedad "justa", donde los ciudadanos se ven obligados a obedecer sus leyes porque son "justas" o "casi justas", la desobediencia civil también tiene vigencia en cuanto mecanismo de presión social para hacer que la sociedad en cuestión sea aún más justa. En una línea convergente, Markowitz (2005) sostiene que los ciudadanos tienen la obligación general de respetar las leyes de una sociedad adecuadamente igualitaria y democráticamente inclusiva. Sin embargo, sostiene el autor, la desobediencia civil puede utilizarse como una forma de resistencia para hacer que los procedimientos relacionados sean más equitativos o inclusivos.

\section{SINTESIS: CONCEPTO TRIDIMENSIONAL}

Ha sido posible constatar que, en las tres dimensiones del concepto de democracia analizadas, el gobierno es siempre un elemento subordinado y el pueblo un elemento subordinante. El gobierno, en efecto, no es un fin en si miso. Por el contrario, el gobierno democrático es simplemente forma, instrumento y medio. En cambio, el pueblo es sustancia/materia, agente y fin de la democracia. El pueblo es el elemento subordinante, en tanto es materia y agente. En cuanto fin en si mismo, el pueblo es el punto de partida y de Ilegada. En la democracia, el pueblo establece una relación circular consigo mismo, a través del gobierno, para reconocer y enaltecer su estatus como comunidad compuesta por individuos libres e iguales.

\begin{tabular}{|c|c|c|c|}
\hline \multicolumn{4}{|c|}{ Relación del pueblo consigo mismo a través del gobierno } \\
\hline Pueblo & \multicolumn{2}{|c|}{ Gobierno } & Pueblo \\
\hline \multirow{3}{*}{$\begin{array}{l}\text { Materia } \\
\text { (a) }\end{array}$} & \multicolumn{2}{|c|}{ Forma (b) } & \\
\hline & $\begin{array}{l}\text { Agente } \\
\text { (c) }\end{array}$ & $\begin{array}{l}\text { Instrumento } \\
\text { (d) }\end{array}$ & \\
\hline & \multicolumn{2}{|c|}{ Medio (e) } & Fin $(f)$ \\
\hline
\end{tabular}

Esta tabla expresa esquemáticamente una implicación: $(a) \rightarrow(b) \rightarrow(c) \rightarrow(d) \rightarrow(e) \rightarrow(f)$. El pueblo-materia (a) produce una forma (b). Esta forma da lugar a la existencia del pueblo como agente del auto-gobierno (c). Ya que el pueblo toma una posición de agente, puede participar en la dinámica política de su instrumento (d). El pueblo se reconoce a sí mismo como soberano en la forma 
política, al utilizarla como instrumento y al participar en el ejercicio del poder político. El gobierno, por su parte, es el instrumento político que media (e) la relación del pueblo consigo mismo (f).

El gobierno democrático es el medio político que permite el autoreconocimiento del pueblo como soberano y como fin de la política. En el primer sentido, el gobierno afirma la existencia política del pueblo. El gobierno, la forma, es concebida como la acción del soberano. Entretanto, esta forma política reconoce al pueblo como su soberano (como productor de la forma política). En el segundo sentido, es el pueblo-agente quien lleva a cabo la acción de gobernar, al participar en la creación de política pública. El pueblo se dirige a sí mismo estableciendo una relación instrumental con el gobierno, pues el propósito de la democracia está necesariamente en referencia teleológica hacia el mismo pueblo.

En el concepto de democracia, como se ha dicho, el gobierno no es elemento subordinante sino subordinado. En cuanto medio para la creación e implementación de política pública, sin embargo, el gobierno democrático actúa con cierta independencia práctica con respecto al pueblo, sin importar que puedan existir distintos grados de apertura a la participación de la comunidad. En una sociedad moderna, marcada por una división del trabajo a gran escala y una diversidad de estilos de vida, la separación de la "propiedad" del poder público en manos del pueblo y los "derechos de uso" en manos del gobierno, es una idea razonable. De hecho, es una distinción que es coherente con el concepto aquí analizado, pues la mencionada separación entre "propiedad" y "derechos de uso" corresponde a la distinción analítica entre las dos primeras dimensiones ("government of the people" y "government by the people"). Es cierto que esta relativa independencia que tiene el gobierno, en cuanto medio de creación e implementación de política pública, puede dar lugar a una idea de subordinación del pueblo con respecto al gobierno. Sin embargo, el ceder a la tentación de considerar que un gobierno, en cuanto medio, es autónomo y subordinante con respecto al pueblo, ha hecho que las instituciones gubernamentales se limiten a mantener funcionando una maquinaria burocrática, desligada de cualquier tipo de misión social.

Al ser un instrumento de auto-reconocimiento del pueblo como soberano, la democracia tiende a mejorar el carácter político de la ciudadanía, pues la deliberación democrática exige a todos escuchar las opiniones de los demás, elaborar un marco de justificación para sus propias ideas, además de incorporar en su propia perspectiva los intereses de los demás. Desde distintos puntos de vista, se ha considerado que la situación de deliberación democrática incentiva a los interlocutores a tomar en consideración, sinceramente, los intereses comunes y la justicia (Elster, 2003). Por tanto, se cree que el proceso democrático tiende a fortalecer la autonomía, la racionalidad, el entusiasmo y la moralidad de los participantes (Hannon, 2020). Al mismo tiempo, la clara determinación de la posición del gobierno democrático como punto medio entre el pueblo y el pueblo mismo, da lugar a un círculo virtuoso, el cual tiende a mejorar también la calidad de la legislación y la política pública. 
Según argumenta Thomas Christiano (2021), es altamente probable que una sociedad de sujetos autónomos, racionales, activos y morales de lugar a un buen gobierno y buenas políticas.

Para establecer y conservar una dinámica de gobierno conforme a las tres dimensiones del concepto de democracia, un gobierno democrático debe desdoblarse como término medio entre el pueblo y el pueblo mismo. El análisis del concepto ha dejado ver con claridad que la democracia no solamente es un procedimiento de toma de decisiones colectivas. Indica quién debe llevar a cabo dicho procedimiento, qué debe hacer, y cómo lo debe hacer.

Como arreglo institucional para lograr la justicia política y social, la democracia establece un sistema de poder igualmente abierto a todos. No solo los ciudadanos tienen la oportunidad formal de acceder al poder y establecer un gobierno cercano a sus preferencias. La democracia puede hacer que las relaciones entre las personas y las instituciones estén mediadas por la racionalidad y la lógica de la subordinación del gobierno con respecto al pueblo.

La democracia es un aparato político que permite la realización de la justicia política y social, donde el poder público se concibe como una especie de bien público, el cual es propiedad colectiva del pueblo. Por lo tanto, el poder político no debe ser monopolizado y todos los ciudadanos deben tener las mismas oportunidades para compartirlo, para participar en el gobierno y para ser beneficiario de las políticas gubernamentales. En este sentido, la democracia cambia la forma en que los gobernantes y el público se relacionan, invirtiendo la jerarquía gobernante-gobernado. La relación se transforma en una relación entre servidor y servido.

El concepto de democracia impone un estándar alto para la práctica política. Sin embargo, en muchos casos, para los regímenes democráticos realmente existentes, la subordinación del gobierno al pueblo dista mucho de ser armónica. Ya sea en lo relacionado con el reconocimiento del pueblo como soberano, ya sea en lo que tienen que ver con la realización de la justicia, la subordinación del gobierno con respecto al pueblo no siempre es evidente. En tal sentido, se ha demostrado que es teóricamente posible que el reconocimiento de la soberanía del pueblo entre en conflicto con los intereses de la justicia distributiva (Van Parijs, 2011). En general, es evidente que, en las democracias realmente existentes, las tres dimensiones están muchas veces en corto circuito.

Existen al menos tres opciones razonables ante la interrupción del sentido político de la democracia y el contraste entre el concepto y su existencia actual. Como primera alternativa, podríamos simplemente negar la denominación de "democrático" a muchos regímenes que se hacen llamar así. Una segunda posibilidad sería aniquilar el contenido multidimensional del concepto de democracia y reducir el modelo a su existencia real. Una tercera opción, más consistente, consiste en procurar elevar la práctica real política al nivel del concepto, entendiendo que la construcción de la democracia es un proceso de constante mejora. 
La filosofía de la democracia pretende esclarecer el contenido y alcance de este concepto, con el propósito de último de contribuir a perfeccionar la práctica política. Desde este punto de vista, si tenemos en cuenta que "la justicia es la principal virtud de las instituciones sociales" (Rawls, 1999, p. 3), es necesario concluir en que el concepto de democracia involucra necesariamente una referencia circular al pueblo, con lo cual la justicia social es una aspiración irrenunciable.

\section{CONSIDERACIONES FINALES}

La unidad y simultaneidad entre las distintas dimensiones analíticas del concepto de democracia no necesariamente es el caso en la mayor parte de las democracias realmente existentes. La teoría de la elección social ha demostrado que los procedimientos democráticos no son intrínsecamente justos, dado que los procedimientos democráticos no necesariamente transforman un conjunto de preferencias individuales en preferencias colectivas racionales (Riker, 1982). En virtud de este posible corto circuito, el discurso hegemónico sobre la democracia ha reducido el concepto a una mera ideología, carente de contenido material.

En el proceso de promover la democracia, el discurso formalista ha oscurecido su contenido conceptual y enrarecido la diferencia entre una democracia reducida a las formalidades y una democracia sustancial o material, la cual asume el gobierno como un punto medio entre el pueblo y el pueblo mismo. En el marco de la circularidad del concepto, la democracia se concibe como un medio para lograr el objetivo de la equidad social y la justicia. Cuando la democracia queda reducida a una mera formalidad, no puede resolver los problemas básicos de la sociedad y no puede conducir a un desarrollo social equitativo. En consecuencia, al exponer a la sociedad a condiciones de injusticia extrema, los gobiernos democráticos pierde la capacidad de desempeñar eficazmente un papel de líder en la construcción de consensos.

El actual sistema democrático pluralista está lejos de ser perfecto. Las fallas inherentes a las formas democráticas existentes pueden estar arruinando el futuro de la democracia. La eficacia de la democracia se ha visto limitada quizás porque la preferencia por este régimen político ha hecho parte de miradas ideológicamente influenciadas. En virtud de dicho sesgo, la democracia ha quedado reducida a solo una de las dimensiones que componen el concepto, imposibilitando una mejora integral.

La natural contradicción social puede dar lugar a conflictos radicales en cuanto a los valores básicos de la democracia, las leyes o las políticas públicas adecuadas, lo que afecta la consolidación de este modelo. Más que un mecanismo para suprimir determinados intereses en disputa, la democracia se presenta como un conjunto de mecanismos para resolver esos conflictos, mediante el diálogo y la participación en los procesos de política pública. Es importante tener en cuenta que el conflicto de intereses es esencial para cualquier democracia, pues las diferencias de criterio son connaturales al pueblo como tal, por lo cual es necesario aceptar y reconocer que una sociedad democrática no puede, ni debe, ser completamente uniforme. 
La democracia es un modelo de gobierno que toma al pueblo como principal elemento de valor y evaluación. En la democracia se asigna un estatus principal al pueblo como núcleo de valor, por lo que este modelo requiere que el valor central del pueblo se vea efectivamente reflejado en las distintas dimensiones del concepto de democracia, de manera que el estado pueda ser la personificación de los intereses y valores del pueblo.

La corrupción y la falta de transparencia están debilitando gravemente la credibilidad de los gobiernos democráticos y poniendo en peligro el estado de derecho. Ninguna sociedad o contrato social puede funcionar sin integridad y confianza (Luhmann, 1996). La corrupción es una seria amenaza para el desarrollo sostenible y la moral social. En medio de la corrupción, los países en desarrollo se han visto estancados en un marasmo de falacias políticas vestidas con ropajes democráticos. Las empresas capaces de ofrecer mejores condiciones laborales y mayor valor agregado, buscan otros contextos que ofrecen mejores condiciones en el entorno político.

Sin duda alguna, una democracia moderna necesita un buen liderazgo, el cual implemente políticas de manera eficaz y participativa, capaz de hacer evidentes los cambios ante los ojos de la población. En lugar de crear turbulencia social, el sello distintivo de un sistema democrático estable y exitoso es una sociedad civil fuerte y participativa.

La realización de la democracia como gobierno para el pueblo (tercera dimensión analítica del concepto) encuentra un desafío mayor al tener que hacer frente a los efectos de la globalización económica. A fin de proporcionar condiciones favorables y atraer capital inversionista extranjero, se ha alterado el equilibrio entre capital, trabajo y bienestar social. Al reducir los impuestos sobre el mercado de capitales, los gobiernos democráticos de países emergentes han reducido el espacio del presupuesto público, dificultando la implementación de políticas sociales y ambientales.

La tendencia actual de la globalización económica neoliberal ha impuesto reformas regresivas a los países, como requisito para la integración económica internacional, afectando negativamente la consolidación de la democracia nacional como gobierno para el pueblo. En medio de los problemas y costos sociales asociados a las estrategias económicas impuestas, los gobiernos democráticos han quedado carentes de recursos suficientes y capacidades institucionales para hacer frente a las crisis, provocando la ingobernabilidad y afectando aún más la confianza del pueblo en el sistema democrático.

La sociedad democrática garantiza que la sociedad civil desempeñe un papel activo en el establecimiento de prioridades y procesos de toma de decisiones, y permite que la administración comprenda las necesidades de los más vulnerables. Esto permite que el gobierno se concentre en promover el desarrollo al enfocarse en tareas como erradicar la pobreza, proteger el medio ambiente, garantizar la igualdad de género y proporcionar medios de vida sostenibles. De hecho, es probable que un país con un gobierno auténticamente democrático esté lleno de violencia y pobreza. Cuando 
se da la voz a las personas vulnerables y se les permite hablar y reivindicar sus derechos humanos, es poco probable que se acuda a la violencia como medio para solucionar los problemas. Al dar voz al pueblo, es posible que el gobierno invierta en las políticas adecuadas para reducir la pobreza. El gobierno democrático proporciona una plataforma para la distribución justa de los beneficios del crecimiento económico y la construcción de una sociedad igualitaria y libre.

Solo a través de la democracia, basada en el respeto de los derechos ciudadanos, la sociedad puede generar confianza social y generar un tejido comunitario capaz de perseverar en las crisis, mantener la resiliencia del país en tiempos de dificultades, eliminar las profundas diferencias sociales a través de la participación y el diálogo inclusivos y tener confianza en que las pérdidas serán compartidas.

Sólo a través de la democracia pueden las organizaciones civiles independientes, incluidas las mujeres y los jóvenes, cooperar con las instituciones públicas para ayudar a proporcionar servicios, mantener informados a los ciudadanos, participar y mejorar la moral social, y tener objetivos comunes. Solo en una democracia los medios independientes pueden desempeñar un papel para mantener a las personas informadas, permitiéndoles tomar decisiones personales y familiares razonables, supervisando al gobierno y las instituciones públicas y combatiendo la falsa información diseñada para socavar la sociedad. Solo un sólido estado de derecho democrático es capaz de proteger la libertad individual de las intrusiones y restricciones impuestas por los gobiernos, que suelen ir mucho más allá de lo necesario, como ha sido el caso para contener la pandemia. Solo en los países democráticos puede la rendición de cuentas pública controlar y limitar los poderes de emergencia del gobierno, y suprimirlos, cuando dejan de ser necesarios.

\section{BIBLIOGRAFIA}

ACE, 2014, "Proportional Representation (PR)". ACE Electoral Knowledge Network. Retrieved 9 April 2014.

Acemoglu, Daron; Suresh Naidu, Pascual Restrepo and James A. Robinson, 2019, "Democracy Does Cause Growth", Journal of Political Economy, 127(1): 47-100. doi:10.1086/700936

Albertus, M and Menaldo, V, 2012, "Coercive Capacity and the Prospects for Democratisation", Comparative Politics 44 (2). pp 151-169.

Anderson, Elizabeth, 2006, "The Epistemology of Democracy", Episteme, 3(1-2): 8-22. doi:10.3366/ epi.2006.3.1-2.8

Arellano, 2015, Mecanismos de democracia directa en América Latina. México. En Contexto (50). CESOPCámara de Diputados

Bajaj, Sameer, 2014, "Review of Democratic Reason: Politics, Collective Intelligence, and the Rule of the Many, by Hélène Landemore", Ethics, 124(2): 426-431. doi:10.1086/673507

Barak, A, 2006, The Judge in a Democracy, Princeton University Press.

Barry, Brian, 1965, Political Argument, London: Routledge \& Kegan Paul. 


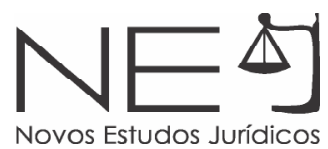

Becker, P, Heideking, J, \& Henretta, J., 2002, Republicanism and Liberalism in America and the German States, 1750-1850, Cambridge University Press.

Bedau, Hugo A., 1961, "On Civil Disobedience", Journal of Philosophy, 58(21): 653-665. doi:10.2307/2023542

Beitz, Charles R., 1989, Political Equality: An Essay on Democratic Theory, Princeton, NJ: Princeton University Press

Birch, A., 1993, The Concepts and Theories of Modern Democracy, Routledge.

Black, Duncan, 1963, The Theory of Committees and Elections, second edition, Cambridge: Cambridge University Press

Brennan, Jason, 2014, "How Smart Is Democracy? You Can't Answer That Question a Priori", Critical Review, 26(1-2): 33-58. doi:10.1080/08913811.2014.907040

Brownlee, 2007, "The Communicative Aspects of Civil Disobedience and Lawful Punishment", Criminal Law and Philosophy, 1(2): 179-192. doi:10.1007/s11572-006-9015-9

Brownlee, 2012, Conscience and Conviction: The Case for Civil Disobedience, Oxford: Oxford University Press.

Brownlee, Kimberley, 2004, "Features of a Paradigm Case of Civil Disobedience", Res Publica, 10(4): 337-351. doi:10.1007/s11158-004-2326-6

Cassese, Antonio, 1995, Self-Determination of Peoples: A Legal Reappraisal, Cambridge: Cambridge University Press

Christiano, Thomas, 1996, The Rule of the Many: Fundamental Issues in Democratic Theory, Boulder, CO: Westview Press.

Christiano, Thomas, 1996, The Rule of the Many: Fundamental Issues in Democratic Theory, Boulder, CO: Westview Press.

Christiano, Thomas, 2008, The Constitution of Equality: Democratic Authority and Its Limits, Oxford: Oxford University Press. doi:10.1093/acprof:oso/9780198297475.001.0001

Christiano, Thomas, 2011, "An Instrumental Argument for a Human Right to Democracy: An Instrumental Argument for a Human Right to Democracy", Philosophy \& Public Affairs, 39(2): 142-176. doi:10.1111/j.1088-4963.2011.01204.x

Christiano, Tom and Sameer Bajaj, (2021), "Democracy", The Stanford Encyclopedia of Philosophy (Fall 2021 Edition), Edward N. Zalta (ed.), forthcoming URL = <https://plato.stanford.edu/archives/fall2021/entries/ democracy/>.

Cohen, Joshua, 1996 [2003], "Procedure and Substance in Deliberative Democracy", in Democracy and Difference: Contesting the Boundaries of the Political, Seyla Benhabib (ed.), Princeton, NJ: Princeton University Press, 95-119; reprinted in Christiano 2003: 17-38.

Cohen, Joshua, 1986, "An Epistemic Conception of Democracy", Ethics, 97(1): 26-38. doi:10.1086/292815

Condorcet, Marquis de, 1785, Essai surl'application de l'analyse à la probabilité des décisions rendues àla pluralité des voix, Paris; reprinted Cambridge: Cambridge University Press, 2014. DOI: 10.1017/CBO9781139923972

Crouze, Ivan, 2014, Democratic innovations: reshaping public governance? The journal of field actions, Field Actions Science Reports, Special Issue 11, october 2014

Dahl, R., 1991, Democracy and its Critics, Yale University Press.

Davenport, Ch., 2007, State Repression and the Domestic Democratic Peace, Cambridge University Press. 
Elster, Jon, 1986 [2003], "The Market and the Forum: Three Varieties of Political Theory", in Foundations of Scoial Choice Theory, Jon Elster and Aanund Hyllund (eds.), Cambridge: Cambridge University Press, 103-132. , 1998, Deliberative Democracy, Cambridge University Press.

Ely, John Hart, 1980, Democracy and Distrust: A Theory of Judicial Review, Cambridge, MA: Harvard University Press.

Estlund, David, 1997, "The Epistemic Dimension of Democratic Authority":, The Modern Schoolman, 74(4): 259-276. doi:10.5840/schoolman199774424

2008, Democratic Authority: A Philosophical Framework, Princeton: Princeton University Press

Everdell, W., 2000, The End of Kings: A History of Republics and Republicans. University of Chicago Press.

Gaus, Gerald F., 1996, Justificatory Liberalism: An Essay on Epistemology and Political Theory, New York: Oxford University Press.

Gaus, Gerald F., 2011, The Order of Public Reason: A Theory of Freedom and Morality in a Diverse and Bounded World, Cambridge: Cambridge University Press. doi:10.1017/CBO9780511780844

Giddens, A., 1984, The Constitution of Society, Cambridge Polity Press.

Goodin, Robert E. and Kai Spiekermann, 2019, An Epistemic Theory of Democracy, Oxford: Oxford University Press. doi:10.1093/oso/9780198823452.001.0001

Gould, Carol C., 1988, Rethinking Democracy: Freedom and Social Cooperation in Politics, Economics and Society, New York: Cambridge University Press.

Grofman, Bernard and Scott L. Feld, 1988, "Rousseau's General Will: A Condorcetian Perspective", American Political Science Review, 82(2): 567-576. doi:10.2307/1957401

Habermas, Jürgen, 1996, Between Facts and Norms: Contributions to a Discourse Theory of Law and Democracy, William Rehg (trans.), Cambridge, MA: MIT Press, 1996

Haldane, R., 1918, The future of democracy, Headley Bros. Publishers Ltd.

Hannon, Michael, 2020, "Empathetic Understanding and Deliberative Democracy", Philosophy and Phenomenological Research, 101(3): 591-611. doi:10.1111/phpr.12624

Hong, Lu and Scott E. Page, 2004, "Groups of Diverse Problem Solvers Can Outperform Groups of High-Ability Problem Solvers", Proceedings of the National Academy of Sciences, 101(46): 16385-16389. doi:10.1073/ pnas.0403723101

IDEA, 2005, "Electoral System Design: the New International IDEA Handbook". International Institute for Democracy and Electoral Assistance. 2005. Retrieved 9 April 2014.

Inglehart, R., 1997, "Modernisation and Postmodernisation. Cultural, Economic, and Political Change", in Societies (43), Princeton University Press.

Kelsen, H., 1955, Ethics, Vol. 66, No. 1, Part 2: Foundations of Democracy (October, 1955), pp. 1-101.

Kimber, R., 1989. “On Democracy". Scandinavian Political Studies 12 (3): 201, 199-219.

Ladha, Krishna K., 1992, "The Condorcet Jury Theorem, Free Speech, and Correlated Votes", American Journal of Political Science, 36(3): 617-634. doi:10.2307/2111584

Landemore, Hélène, 2013, Democratic Reason: Politics, Collective Intelligence, and the Rule of the Many, Princeton, NJ: Princeton University Press. 
Lincoln, A., 1864, The Gettysburg Address, Gettysburg, Pennsylvania, November 19, 1864, http://showcase. netins.net/web/creative/lincoln/speeches/gettysburg.htm.

List, Christian and Robert E. Goodin, 2001, "Epistemic Democracy: Generalizing the Condorcet Jury Theorem", Journal of Political Philosophy, 9(3): 277-306. doi:10.1111/1467-9760.00128

Locke, John, 1690, Second Treatise on Civil Government, London; reprinted C.B. MacPherson (ed.), Indianapolis, IN: Hackett, 1980.

Lowenstein, K., 1959, Verfassungslehre, Tubingen.

Macpherson, C., 1977, The Life and Times of Liberal Democracy, Oxford University Press.

Markovits, Daniel, 2005, “Democratic Disobedience", Yale Law Journal, 114(8): 1897-1952.

Marx, K., 2010, «Critique du droit politique hégélien», Allia, Paris.

Mill, John Stuart, 1861 [1991], Considerations on Representative Government, London: Parker, Son, and Bourn; reprinted Buffalo, NY: Prometheus Books, 1991

Mill, John Stuart, 1861 [1991], Considerations on Representative Government, London: Parker, Son, and Bourn; reprinted Buffalo, NY: Prometheus Books, 1991

Ober, J and Hedrick, C., 1996, Dēmokratia: a conversation on democracies, ancient and modern, Princeton University Press.

Page, Scott E., 2007, The Difference: How the Power of Diversity Creates Better Groups, Firms, Schools, and Societies, Princeton, NJ: Princeton University Press.

Pinker, S., 1994, The Language Instinct: The New Science of Language and Mind, Penguin.

Pinker, S., 2007, The Stuff of Thought: Language as a Window into Human Nature, Penguin.

Pitkin, Hanna Fenichel, 1967, The Concept of Representation, Berkeley, CA: University of California.

Quirk, Paul J., 2014, "Making It up on Volume: Are Larger Groups Really Smarter?", Critical Review, 26(1-2): 129-150. doi:10.1080/08913811.2014.907046

Rawls, John, 1971, A Theory of Justice, Cambridge, MA: Harvard University Press.

Raz, Joseph, 1979, The Authority of Law: Essays on Law and Morality, Oxford: Clarendon Press.

Reveles Vázquez, 2017, Democracia participativa para el fortalecimiento de la representación política. La experiencia latinoamericana, Andamios vol.14 no.35 México sep./dic. 2017

Riker, William H., 1982, Liberalism Against Populism: A Confrontation Between the Theory of Democracy and the Theory of Social Choice, San Francisco, CA: W. H. Freeman.

Rousseau, Jean-Jacques, 1762, Du contrat social; ou Principes du droit politique, Amsterdam. Translated as The Social Contract, Charles Frankel (trans.), New York: Hafner Publishing Co., 1947.

Sabl, Andrew, 2001, "Looking Forward to Justice: Rawlsian Civil Disobedience and Its Non-Rawlsian Lessons", Journal of Political Philosophy, 9(3): 307-330. doi:10.1111/1467-9760.00129

Sen, Amartya, 1999, "Democracy as a Universal Value", Journal of Democracy 10 (3)

Sen, Amartya, 1999, Development as Freedom, New York: Knopf.

Simmons, 2007, Political Philosophy, Oxford: Oxford University Press. 
Novos Estudos Jurídicos

Simmons, A. John, 2001, Justification and Legitimacy: Essays on Rights and Obligations, Cambridge: Cambridge University Press. doi:10.1017/CBO9780511625152

Singer, Peter, 1973, Democracy and Disobedience, Oxford: Clarendon Press

Smith, William, 2011, "Civil Disobedience and the Public Sphere", Journal of Political Philosophy, 19(2): 145166. doi:10.1111/j.1467-9760.2010.00365.x

Stilz, Anna, 2009, Liberal Loyalty: Freedom, Obligation, and the State, Princeton, NJ: Princeton University Press.

The economist, 2013, "Democracy index 2012: Democracy at a standstill". Economist Intelligence Unit. 14 March 2013.

Thompson, Abigail, 2014, "Does Diversity Trump Ability?" Notices of the AMS, 61(9): 1024-1030.

Van Parijs, Ph., 2011, Just Democracy. The Rawls-Machiavelli program, Ecpr Press, Colchester.

Waldron, Jeremy, 1995, "The Wisdom of the Multitude: Some Reflections on Book 3, Chapter 11 of Aristotle's Politics", Political Theory, 23(4): 563-584. doi:10.1177/0090591795023004001

Waldron, Jeremy, 1999, Law and Disagreement, Oxford: Clarendon Press

Willard, Ch (1996), Liberalism and the Problem of Knowledge: A New Rhetoric for Modern Democracy, University of Chicago Press.

Wood, E (1995), Democracy Against Capitalism: Renewing historical materialism, Cambridge University Press.

Wright, Gavin, 2013, Sharing the Prize: The Economics of the Civil Rights Revolution in the American South, Cambridge, MA: Harvard University Press

Recebido em: 02/03/2021

Aprovado em: 26/04/2021 